\title{
Recent Developments in the Purex Process for Nuclear Fuel Reprocessing: Complexant Based Stripping for Uranium/Plutonium Separation
}

\author{
J. Eddie Birkett, Michael J. Carrott, O. Danny Fox, Chris J. Jones, Chris J. Maher, \\ Cécile V. Roube, Robin J. Taylor*, and David A. Woodhead
}

\begin{abstract}
In order to recycle potentially valuable uranium and plutonium, the Purex process has been successfully used to reprocess spent nuclear fuel for several decades now at industrial scales. The process has developed over this period to treat higher burnup fuels, oxide as well as metal fuels within fewer solvent extraction cycles with reduced waste arisings. Within the context of advanced fuel cycle scenarios, there has been renewed international interest recently in separation technologies for recovering actinides from spent fuel. Aqueous fuel processing research and development has included further enhancement of the Purex process as well as the development of minor actinide partitioning technologies that use new extractants. The use of single cycle Purex solvent extraction flowsheets and centrifugal contactors are key objectives in the development of such advanced Purex processes in future closed fuel cycles. These advances lead to intensified processes, reducing the costs of plants and the volumes of wastes arising. By adopting other flowsheet changes, such as reduced fission product decontamination factors, U/Pu co-processing and Pu/Np co-stripping, further improvements can be made addressing issues such as proliferation resistance and minor actinide burning, without adverse effects on the products. One interesting development is the demonstration that simple hydroxamic acid complexants can very effectively separate $U$ from $\mathrm{Np}$ and $\mathrm{Pu}$ in such advanced Purex flowsheets.
\end{abstract}

Keywords: Acetohydroxamic acid · Actinides · Centrifugal contactors · Nuclear fuel reprocessing ·

Purex process

\section{Introduction}

Nuclear fuel reprocessing [1] is the separation and purification of reusable uranium and plutonium products from irradiated nuclear fuel. The recovered $\mathrm{U}$ and Pu can then be converted in to new uranium oxide (UOx) or mixed oxide (MOx) fuels for recycle to reactors. The highly active (HA) fission product wastes are evaporated and

${ }^{*}$ Correspondence: Dr. R. Taylo

Nexia Solutions Ltd.

BNFL Technology Centre

Sellafield

CA20 1PG

United Kingdom

Tel.: 441946779266

Fax: 441946779007

E-Mail: robin.j.taylor@nexiasolutions.com then vitrified ready for disposal. By far the most successful reprocessing technology to date has been the Purex process, which uses solvent extraction between aqueous nitric acid solutions and organic solutions of tri- $n$-butyl phosphate (TBP) diluted in a paraffinic diluent, such as Exxon D-80. Reprocessing plants in the United Kingdom, France, Japan and Russia all use versions of the Purex process and it is likely that Purex will remain the basis of any future aqueous reprocessing technology developed for advanced fuel cycles such as 'Generation IV' reactors.

The separation of $\mathrm{U}$ and $\mathrm{Pu}$ from fission products is achieved by extraction of hexavalent and tetravalent metal nitrate complexes (Eqn. (1) and (2)) followed by reductive stripping of $\mathrm{Pu}$, whereby the extractable tetravalent $\mathrm{Pu}$ is reduced to inextractable trivalent $\mathrm{Pu}$ and stripped to an aqueous phase, leaving $\mathrm{U}(\mathrm{VI})$ in the organic phase. Typically, a reductant such as uranous nitrate $\{\mathrm{U}(\mathrm{IV})\}$ is used for this purpose (Eqn. (3)) [2].
$\mathrm{Pu}^{4+}+4 \mathrm{NO}_{3}^{-}+2 \mathrm{TBP} \leftrightarrow$

$\mathrm{Pu}\left(\mathrm{NO}_{3}\right)_{4} \cdot 2 \mathrm{TBP}$

$\mathrm{UO}_{2}{ }^{2+}+2 \mathrm{NO}_{3}^{-}+2 \mathrm{TBP} \leftrightarrow$

$\mathrm{UO}_{2}\left(\mathrm{NO}_{3}\right)_{2} \cdot 2 \mathrm{TBP}$

$2 \mathrm{Pu}^{4+}+\mathrm{U}^{4+}+2 \mathrm{H}_{2} \mathrm{O} \leftrightarrow$

$2 \mathrm{Pu}^{3+}+\mathrm{UO}_{2}{ }^{2+}+4 \mathrm{H}^{+}$

A complication is that $\mathrm{Pu}(\mathrm{III})$ is quite easily re-oxidised to $\mathrm{Pu}(\mathrm{IV})$ by nitric acid in a series of reactions that is autocatalysed by nitrous acid (Eqn. (4) and (5)). To interrupt this process and stabilise $\mathrm{Pu}$ as $\mathrm{Pu}(\mathrm{III})$, an aqueous phase nitrous acid scavenger such as hydrazine is added to the U/Pu separation contactor (Eqn. (6) and (7)) [2].

$\mathrm{Pu}^{3+}+\mathrm{HNO}_{2}+\mathrm{H}^{+} \rightarrow \mathrm{Pu}^{4+}+\mathrm{NO}+\mathrm{H}_{2} \mathrm{O}$

$2 \mathrm{NO}+\mathrm{HNO}_{3}+\mathrm{H}_{2} \mathrm{O} \rightarrow 3 \mathrm{HNO}_{2}$

$\mathrm{N}_{2} \mathrm{H}_{4}+\mathrm{HNO}_{2} \rightarrow \mathrm{HN}_{3}+2 \mathrm{H}_{2} \mathrm{O}$ 
$\mathrm{NH}_{3}+\mathrm{HNO}_{2} \rightarrow \mathrm{N}_{2}+\mathrm{N}_{2} \mathrm{O}+\mathrm{H}_{2} \mathrm{O}$

However, although it is nominally considered to be 'inextractable', trace quantities of $\mathrm{Pu}(\mathrm{III})$ are extracted into the solvent phase where, in the absence of a scavenger, re-oxidation to $\mathrm{Pu}(\mathrm{IV})$ does occur. In twophase mixed systems this process is enhanced as the system tries to equilibrate; the ultimate effect being a requirement to add a substantial excess of reductant to maintain $\mathrm{Pu}$ in the trivalent state [2].

\section{Purex Process Development and International Experience}

The Purex process was developed in the late 1940s in the United States. Previously large-scale plutonium and fuel processing used a bismuth phosphate precipitation method; this was then superseded by solvent extraction processes that could be run continuously. The Redox process using methyl isobutyl ketone or hexone as the solvent was used at the Hanford site in the USA and the Butex process using dibutyl carbitol was used in the UK at Windscale. However, the Purex process was quickly shown to possess a number of process chemistry and chemical engineering advantages over these other processes and has remained the dominant technology for processing nuclear fuel since the 1950s/60s [3].

A Purex reprocessing plant comprises a number of facilities: (a) a head end plant to receive and store spent fuel and to convert the fuel to a solution in $\mathrm{HNO}_{3}$ ready for (b) chemical separation using solvent extraction to produce separate aqueous nitrate products that can be (c) converted to solid oxide products. A substantial supporting infrastructure (d) is necessary to treat solid wastes and liquid and gaseous effluents arising from reprocessing operations [1] [4]. A schematic representation is given in Fig. 1 for a typical oxide fuel reprocessing facility.

Large-scale Purex reprocessing plants ( 800 te/a) are in operation in the UK (Sellafield), France (La Hague), and Japan (commissioning at Rokkasho) but a number of other countries have past experience of Purex reprocessing at various scales, e.g. USA, Germany, Russia, Belgium, India [1][2][4].

Chemical separation flowsheets are all broadly similar, using a number of solvent extraction cycles to separate and purify $U$ and $\mathrm{Pu}$ from all other elements. Process development has been in the direction of reducing the number of solvent extraction cycles, adopting an early separation of $\mathrm{Pu}$ from $U$, using salt-free reagents to minimise waste arisings and intensifying the contacting equipment, e.g. pulsed columns rather than mixer-settlers.

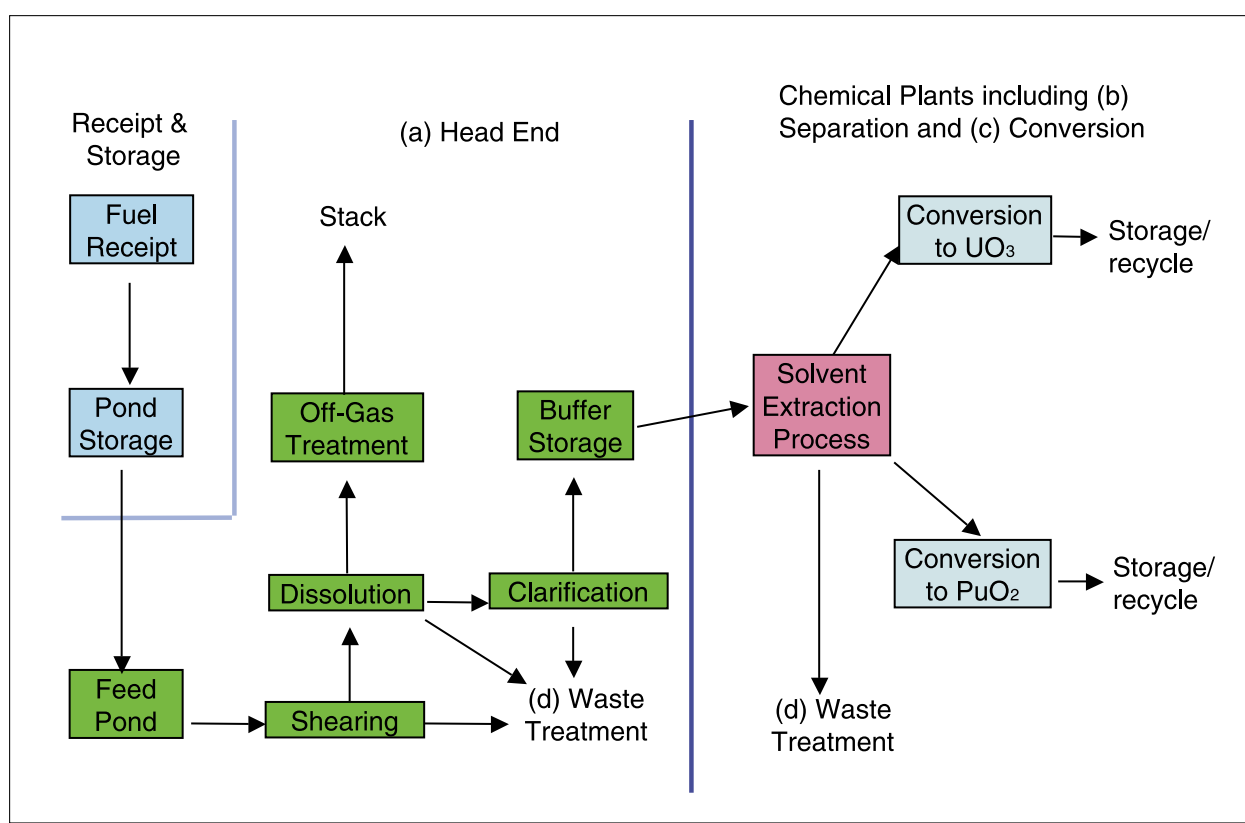

Fig. 1. Schematic representation of a typical configuration for an oxide fuel reprocessing plant using the Purex process, indicating (a) Head End, (b) Chemical Separation, (c) Product Conversion and (d) Waste and Effluent Management

The Thermal Oxide Reprocessing Plant (Thorp) at the British Nuclear Group Sellafield site, UK, exemplifies this approach. It uses three solvent extraction cycles with an early split flowsheet compared to four cycles and a late split used by the earlier Magnox reprocessing plant on the Sellafield site. Ferrous sulphamate and sodium nitrite reagents used by Magnox are replaced by salt-free reagents, U(IV) and nitrogen oxide gases (NOx). Pulsed columns are used for the Pu-bearing streams and the separations plant is integrated with the other supporting operations. This is achieved despite Thorp processing higher burnup, enriched oxide fuel from Advanced Gas Cooled Reactors (AGRs) and Light Water Reactors (LWRs) as opposed to lower burnup, short cooled, natural enrichment $U$ metal Magnox fuel [1][2][4].

\section{Advanced Fuel Cycles (AFCs)}

In the last ten years or so there has been a growing international interest in future or advanced nuclear fuel cycles and many different scenarios have been proposed around the basic alternatives of open, partially closed or fully closed cycles (with respect to the actinide inventories) [5]. Partially closed cycles in which $\mathrm{Pu}$ is recycled as MOx fuel and fully closed cycles, which recycle all the transuranium (TRU) elements $(\mathrm{Np}, \mathrm{Pu}, \mathrm{Am}, \mathrm{Cm})$, obviously require fuel processing and separations technologies. Whilst $\mathrm{Np}$ and $\mathrm{Pu}$ can be recovered using Purex technology, the recovery of Am and $\mathrm{Cm}$ is more problematic and requires alternative separation methods.
Hence, in recent years there has been renewed interest in the development of enhanced separation processes for the management of spent nuclear fuel within possible future closed fuel cycles [3][5]. Both aqueous partitioning and molten salt pyro-processing are under development, with a particular focus on developing a capability to recycle and burnup (or transmute) the transuranic elements. This is in order to reduce by factors in the order of $10^{3}$ the time taken to reduce nuclear wastes to the activity of the original natural $\mathrm{U}$ component, which would make the long-term management of nuclear waste much easier [6]. There are a number of variations on advanced fuel cycles, but most scenarios share a common aim of recycling TRU actinides for transmutation. This generally requires a move from current thermal reactors to either fast reactors (FR) or accelerator driven systems (ADS) [6]. Notably, four different FR systems are being developed within the 'Generation IV International Forum', which is now probably the most prominent international programme developing advanced reactor systems [7]. Consequently, whether such fuel cycles are based on a measured transition, the so-called 'double strata' approach or a more aggressive transition to fast reactors, actinide recovery and recycle is a common requirement [6]. However, recovery of the trans-Pu (TRPu) elements (Am, Cm) is not achievable within the Purex process and is chemically very difficult due to the very similar properties of these trivalent actinides $\{A n(I I I)\}$ with the trivalent fission product lanthanides in solution. Much effort has therefore been dedicated to the development of new partition- 
ing technologies for the trivalent actinides (chemical separations and fuel fabrication). As well as TRU actinide recycle, further requirements for advanced separation technologies include: increased proliferation resistance; reduced costs and lower environmental impact and a reduced impact on geologic repositories such as Yucca Mountain in the USA [6][8-10].

These drivers have led to substantial research worldwide to either improved aqueous based processes or alternative technology, most notably pyroprocessing in molten halide salt media [11]. Some of the consequent objectives of development programmes for advanced aqueous-based process flowsheets and separation technol-

In the development of aqueous-based separation processes, the Purex process is the well-established basis for recovering $\mathrm{U}$ and $\mathrm{Pu}$, and with slight modifications, $\mathrm{Np}$, I and Tc products $\left({ }^{129} \mathrm{I}\right.$ and ${ }^{99} \mathrm{Tc}$ are long-lived fission products with half lives of 1.6E7 and 2.14E5 years respectively). Various forms of 'advanced' Purex processes have been proposed to enable Purex technology meet the requirements for the recovery of these species in advanced fuel cycles, e.g. [10][15][19]. Recovery of Am, and other species including $\mathrm{Cm}$ and $\mathrm{Cs}, \mathrm{Sr}$ (heat generating fission products) requires the development of alternative processes and extractants.

\section{Current and Recent International Programs}

Some, or all, of these requirements (Table 1) are drivers for a number of major international programmes that have been established in recent years to address growogies are given in Table 1.

ing concerns on future energy and fuel cycle needs.

The French Commissariat à l'Énergie Atomique (CEA) have made very significant progress in developing solvent extraction processes that can partition trivalent actinides from Purex high-level wastes. Their reference process again uses a modified Purex flowsheet to control U, $\mathrm{Pu}$ and $\mathrm{Np}$ followed by new solvent extraction processes termed DIAMEX (Diamide $E x$ traction) and SANEX (Selective Actinide Extraction) [10]. The DIAMEX process uses a malonamide extractant, such as DMDOHEMA (N,N'-dimethyl N,N'-dioctyl hexyloxyethyl malonamide) to co-extract An(III) and Ln(III) ions [20]. Various diamides have been investigated extensively and 'hot' testing on real high-level raffinates and even high-level concentrates following evaporation has been successfully carried out. A centrifugal contactor trial on real high-level wastes (HLW) in 2000, for instance, achieved ca. $99.9 \%$ recovery of Am and $\mathrm{Cm}$ [21][22], and a hot test using highly active concentrate (HAC) recovered 99.7\% Am and 99.9\% Cm [23]. Following co-extraction of the trivalent actinides and lanthanides, the SANEX process is used to separate $\mathrm{Am}$ and $\mathrm{Cm}$ from the lanthanides [10]. A variety of extractants have been proposed within the SANEX framework, but all with the objective of exploiting the small differences in covalency between $5 f$ and $4 \mathrm{f}$ electrons to achieve separation. Neutral multi-N-donor ligands have perhaps proved the most successful with BTP (bistriazinylpyridine) ligands showing quite remarkable selectivity for Am(III) over Ln(III) (Fig. 2 illustrates an example of a BTP ligand). The BTP ligands however are rather unstable in process solutions with respect to radiolysis and hydrolysis and extraction

Table 1. Requirements for advanced aqueous reprocessing and partitioning technologies for AFCs Full TRU actinide recycle for transmutation

Increased proliferation resistance

A requirement for $>99 \%$ separation, recovery and recycle of TRU elements (Np, Pu, Am and possibly $\mathrm{Cm}, \mathrm{Cf}$ ) [6][12]

Flowsheet changes such as co-processing, avoiding separated pure $\mathrm{Pu}$, increased fission product contamination of actinde products (lower decontamination factors [DFs]), co-routing of $\mathrm{Np}$ with $\mathrm{Pu}$ in flowsheets

Reduced waste arisings and lower environmental impact

Development of single cycle solvent extraction flowsheets with lower solvent inventories [3], and/or the use of a crystallisation process [13]

Reduced costs

Smaller intensified plant; the use of centrifugal contactors is widely accepted as the basis for next generation solvent extraction technology [14].

Greater flexibility of processes

An ability to process within the flowsheet much higher burn up fuels, including mixed oxide (MOx), Pu, and FR fuels

Reduced impact on geologic repositories
Consideration of the partitioning of heat generating species such as $\mathrm{Cs}$ and $\mathrm{Sr}$ from high level wastes for decay storage rather than disposal. Also the capability of meeting specifications for the $U$ product that allow the reclassification of $U$ to low level waste (LLW) [12]. kinetics can be slow. Most recent efforts have been directed at finding variants with increased stability [24-26]. The CEA have also proposed a calixarene-based process for Cs separation and an electrochemical process for Am/Cm separation [10][27].

European development of partitioning routes, including DIAMEX and SANEX processes, has been coordinated through the European Commission EURATOM Framework programmes. Projects such as NEWPART, PARTNEW, CALIXPART and most recently EUROPART have investigated a wide range of complexing agents such as BTP and hemi-BTP ligands and calixarenebased ligands for the separation of trivalent actinide and caesium ions from high level wastes [28-31].

The American Advanced Fuel Cycle Initiative (AFCI), is aimed at developing separations and recycle technology for future US spent fuel in order to substantially extend the lifetime of the Yucca Mountain repository [8]. The proposed aqueous process is termed UREX+, which aims to produce a bulk $\mathrm{U}$ product suitable for disposal as low-level waste or recycle to LWRs, and $\mathrm{Pu}-\mathrm{Np}$ and Am products for recycle. $\mathrm{Cs}$ and Sr separations are also planned to reduce the short-term heat loading in the repository, which is one of the major limiting factors on the allowed repository inventory. A number of separation processes are being studied. An advanced Purex process using the complexant acetohydroxamic acid (AHA) for Np and Pu control (see Section 7 below) seems to be accepted as the basis of the Purex flowsheet. Cs/Sr separation using a cobalt dicarbollide extractant or possibly calixarenes and TRPu element separations using the French DIAMEX-SANEX processes appear to be leading options to follow the Purex section, although other options have been tested [12][32][33].

In Japan, the Japan Nuclear Fuel Cycle Development Company (JNC) are leading the development of technology to demonstrate the feasibility of fast reactor (FR) fuel cycles; this includes the back end fuel processing technologies [13][34]. They are investigating both aqueous and pyro-processing routes. On the aqueous side, they propose an interesting innovation utilising crystallisation to remove the bulk of the $U$ from solution followed by a much simplified Purex type process to coextract $\mathrm{U}, \mathrm{Np}$ and $\mathrm{Pu}$ away from the fission product wastes [13]. The actinides are then co-stripped to a $\mathrm{U}-\mathrm{Np}-\mathrm{Pu}$ product ready for product finishing. Am and $\mathrm{Cm}$ are recovered by a modified TRUEX type process termed SETFICS [34]. (The TRUEX [Transuranium Extraction] process was developed by the Argonne National Laboratory (ANL) in the USA in the 1980s to extract TRU elements from wastes. It uses octyl-(phenyl)$\mathrm{N}, \mathrm{N}$-diisobutylcarbamoylmethylphosphine 


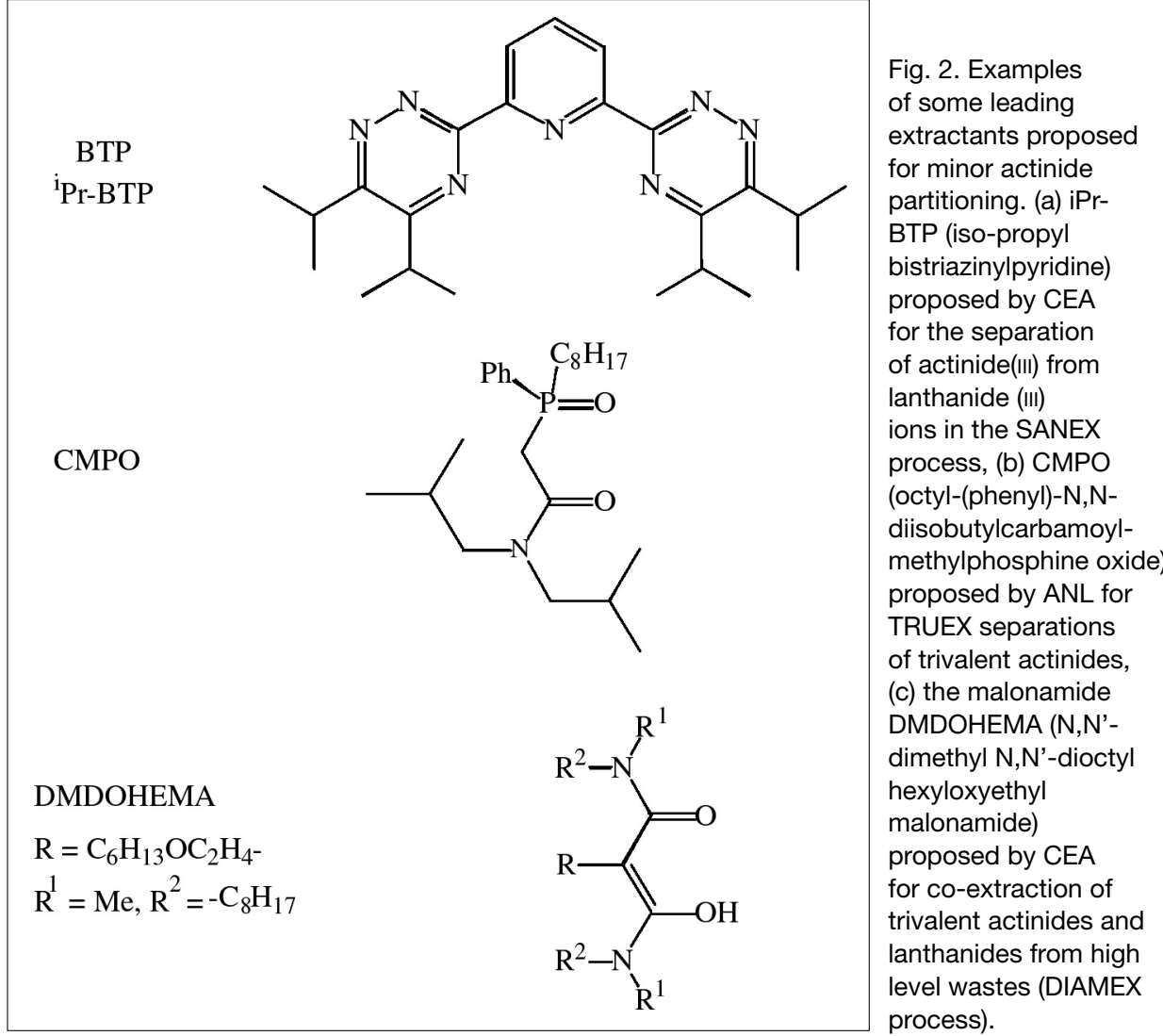

oxide [CMPO] as the extractant (Fig. 2) [11].

There are numerous other aqueous-based processes that have been proposed for the difficult task of separating An(III) from fission products, particularly the trivalent lanthanides (see e.g. [11]). Most of these processes use counter-current solvent extraction technology but the proposed extracting solvents vary. Hybrid processes combining aqueous and volatile fluoride routes, or aqueous and pyro-routes have also been suggested [35]. The Nuclear Energy Agency (NEA) of the Organisation for Economic Co-operation and Development (OECD) have established various working parties to link international developments in partitioning and transmutation (P\&T) technologies and a series of status reports reviewing the progress made by various member states are being published [36-38].

\section{Legacy and Waste Processing}

Besides the development of flowsheets for AFCs, modified aqueous processes can also be applied to deal with processing legacy fuels, actinide wastes, orphan materials and similar problematic materials that many countries and laboratories have left over from nuclear fuel cycle development programmes. For instance, the UK has a wide range of legacy fuels and residues reflecting sixty years' plus pioneering nuclear industry development, including defast reactors using $\mathrm{UOx}, \mathrm{MOx}, \mathrm{Pu}$, highly enriched uranium, carbide, metal fuels etc. In particular, the development of simplified Purex-based flowsheets capable of processing a broad envelope of feeds, including very high Pu loadings, and converting these heterogeneous materials to standard oxide forms, is highly relevant to strategies for the management of such $\mathrm{Pu}$ residues and experimental fuels. Potential applications of simplified flowsheets, initially developed for AFCs, to process UK legacy materials have been reported [39]. Similar work supporting the development of the chemical flowsheet for processing ex-weapons materials in the US and Russian disposition programmes have been reported by Brossard and co-workers (in the context of joint French - Russian - US programmes). They report the development of aqueous processes that include pre-treatment to remove impurities such as chloride and to prepare the feed, a $\operatorname{Ag}$ (II) catalysed dissolution, followed by a Purex Pu purification flowsheet. The solvent extraction flowsheet is based on Purex technology, with a hydroxylamine nitrate (HAN) reductant stabilised by hydrazine [40][41].

\section{Advanced Purex Process Development}

Considering the proven utility and established operational experience, the de- velopment of advanced or modified Purex processes must be a major component of any programme considering aqueous-based technology for fuel processing. The focus of such programmes is generally to meet the criteria listed in Table 1. Hence, the actinides U, $\mathrm{Np}$ and $\mathrm{Pu}$ need to be fully controlled within a single Purex solvent extraction cycle that is flexible to a wide range of feeds. The process must probably meet high product specifications on the $\mathrm{U}$ stream, with $\mathrm{Pu}$ streams that offer increased proliferation resistance. This must be achieved within short residence time annular centrifugal contactors, using kinetically fast 'CHON' [42] reagents only [27], producing minimised volumes of easily treated product and effluent streams.

Notable early progress in the development of such advanced reprocessing flowsheets was the German IMPUREX process. However, the aims of this work were to achieve high purity products (high fission product decontamination factors [DFs]) rather than TRU actinide recovery and other requirements for AFCs, as given in Table 1. They proposed using a high degree of feed clarification coupled with a very high saturation flowsheet to achieve very high fission product DFs in the first contactor [43][44].

A potentially useful innovation is complexant-based rather than reductive stripping of $\mathrm{Np}$ and $\mathrm{Pu}$ using simple hydroxamic acids [45-49].

\section{Complexant-Based Stripping}

\subsection{Introduction}

As discussed previously, current Purex flowsheets use reductive stripping to separate $\mathrm{Pu}$ from $\mathrm{U}$ by exploiting the change in $\mathrm{Pu}$ extractability as the oxidation state changes from IV to III. Fe(II), U(IV) and HAN are commonly used reducing agents. The reductant must be used in combination with a nitrite scavenger such as sulphamic acid or hydrazine [2].

An alternative option is to replace the reductive stripping of $\mathrm{Pu}$ by complexation: $\mathrm{Pu}(\mathrm{IV})$ is selectively complexed by a hydrophilic ligand and stripped in to the aqueous phase, leaving $U$ in the solvent. The advantages of complexation include fast kinetics, relative temperature insensitivity compared to redox reactions and no reoxidation of $\mathrm{Pu}(\mathrm{III})$, hence no need for a stabiliser and likely improved nuclear criticality control. It is also more likely that complexant-based stripping can be extended to fuels that have high $\mathrm{Pu}$ contents (e.g. up to 40 wt. \%), where reductive stripping would be difficult to implement and control due to high reductant concentrations needed to maintain $\mathrm{Pu}$ in the trivalent state.

The most studied ligand for complexant stripping of $\mathrm{Pu}$ is the sulphate anion. Indeed, 
a flowsheet based on sulphate stripping was designed and operated at the UKAEA Dounreay site in the UK for reprocessing fast reactor fuel [2]. This method suffers from the salt-loading of the waste streams and the corrosive nature of the sulphate anion and is not considered suitable for advanced fuel cycles.

Alternatives based on organic anions derived from common weak acids have been proposed; notably, formate, acetate and lactate but these generally are not favoured due to the weak nature of the complexes formed in nitric acid [2][49].

More promising studies on the use of organic complexants led to the proposition of the use of hydroxamic acids for Pu stripping [19]. Interest in the use of hydroxamic acids arose because of the noted differences in the stability constants of $\mathrm{Pu}(\mathrm{IV})$ and $\mathrm{U}(\mathrm{VI})$ for a series of organic soluble hydroxamates, such as benzohydroxamate [50][51]. Hydroxamates are also known to be very good complexing agents for metals with high charge densities (e.g. Fe(III), Pu(IV)) through studies of siderophores and their analogues - naturally occurring biomolecules used by fungi for sequestration of $\mathrm{Fe}$ from the environment [52][53]. For consideration in reprocessing, the simplest hydroxamates, formo- and acetohydroxamic acids, were chosen because they have the least impact on the process, are most easily managed in waste treatment and are the most hydrophilic forms [46].

The stability constants for formo- and acetohydroxamic acids with a range of metal ions have been determined. The stability constants in $\mathrm{HClO}_{4}\left(\log \beta_{1}-\log \beta_{4}\right)$ for the $\mathrm{Pu}(\mathrm{IV}) \mathrm{AHA}$ complexes were found to be 13.9, 24.1, 32.7 and 38.8 compared to 7.94 and $14.11\left(\log \beta_{1}, \log \beta_{2}\right)$ for the U(VI) complexes and a $\mathrm{pK}_{\mathrm{a}}$ for AHA of 9.02. These demonstrate the strong complexation with tetravalent actinides even in very acidic solutions and their specificity for $\mathrm{Pu}(\mathrm{IV})$ over $\mathrm{U}(\mathrm{VI})$ [46][48].

The ability of these hydroxamic acids to strip tetravalent actinides from TBP, in the absence and presence of U(VI) was confirmed by simple solvent extraction batch distribution experiments, in which aqueous and organic phases in a 1:1 ratio, containing $\mathrm{Np}$ (IV), $\mathrm{Pu}(\mathrm{IV}$ ) and (as required) U(VI) in the organic phase and the hydroxamic acid phase are equilibrated [54][55]. Analysis of the metal ions in each phase after equilibration gives a distribution ratio (the ratio of the concentration of the metal ion in the solvent to its concentration in the aqueous phase). Lower distribution coefficients (D), indicate better stripping of the metal ion into the aqueous phase. To generalise, reduced acidity and increased AHA (AHA:Pu ratio) decrease $\mathrm{D}_{\mathrm{Pu}(\mathrm{IV})}$ whereas increased $\mathrm{Pu}$ concentration increases $\mathrm{D}_{\mathrm{Pu}(\mathrm{IV})}$. For an example, Fig. 3 illustrates the relationship between $\mathrm{D}_{\mathrm{Pu}}$ and the AHA:Pu ratio.

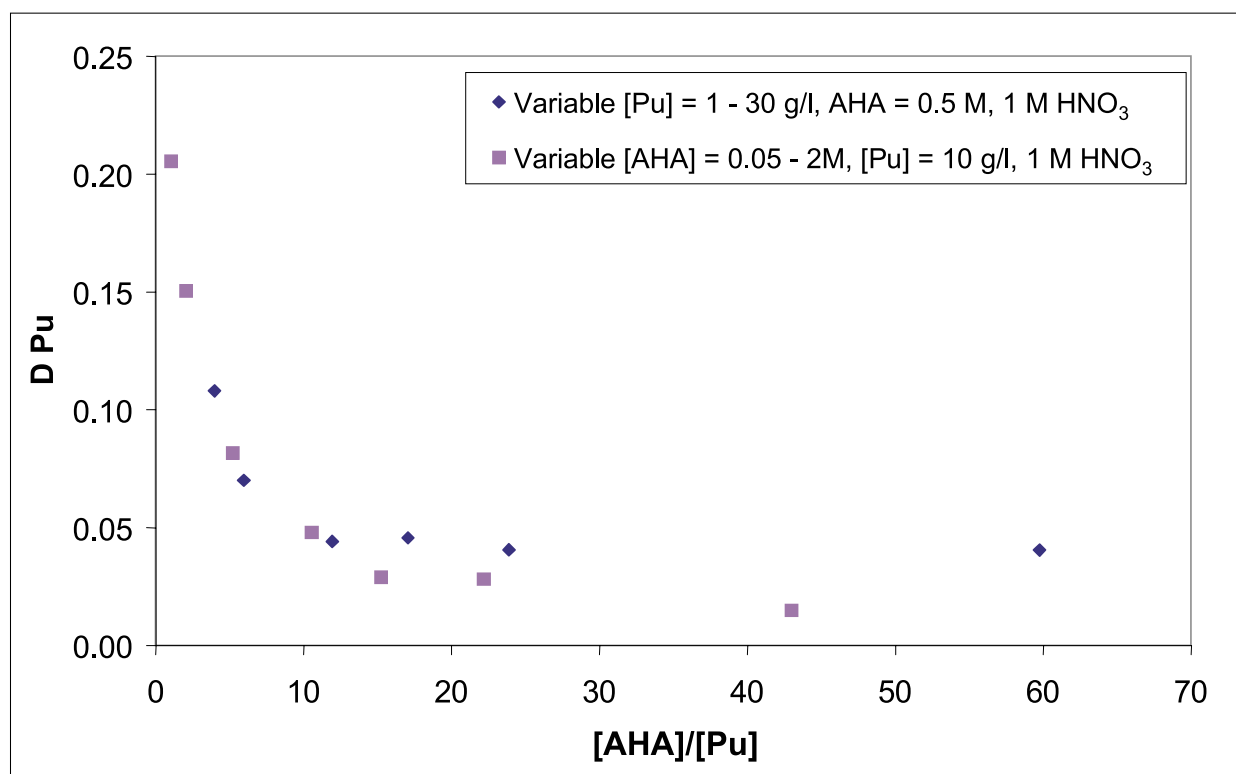

Fig. 3. Effect of acetohydroxamic acid (AHA) concentration on the distribution of Pu at variable Pu and variable AHA concentrations (batch distribution data measured at $25^{\circ} \mathrm{C}$ )

Consequentially, we have been studying the chemistry of simple hydroxamic acids and their applications in Purex reprocessing since the late 1980s.

\subsection{Plutonium Stripping}

The applications of AHA in advanced single cycle Purex flowsheets for separating high levels of $\mathrm{Pu}$ from $\mathrm{U}$ have been tested recently in a series of centrifugal contactor trials [47]. The centrifugal contactor cascade used is shown in Fig. 4. Three flowsheets with increasing $\mathrm{Pu}$ feed concentrations of 7, 20, and 40 wt. $\%$ were tested, representing an increasing challenge on the performance of the flowsheet and the ability of hydroxamic acids to separate $\mathrm{U}$ and $\mathrm{Pu}$. The levels of $\mathrm{Pu}$ in these flowsheets were selected to exemplify processing MOx fuels, FR fuels and, at $40 \mathrm{wt} \%$ $\mathrm{Pu}$, some U.K. legacy materials as well as to provide a strenuous test of the flowsheet. The flowsheet for the $7 \%$ trial $([\mathrm{Pu}]$ in the Highly Active Feed $[\mathrm{HAF}]=18 \mathrm{~g} / \mathrm{l})$ is reproduced in Fig. 5, and the other flowsheets were simply slight modifications on this, with small changes to parameters such as acidities, flowrates, reagent concentrations and the number of stages in the U/Pu split, in order to optimise performance.

A detailed description of the results from these trials is beyond the scope of this current paper. However, the trials were very successful, demonstrating that excellent separation of $\mathrm{U}$ and $\mathrm{Pu}$ is achievable using AHA, even at very high Pu feeds; this is illustrated in Table 2, which shows some key data from the trials. The first trial obtained a very high $\mathrm{U}$ DF on the Pu stream (1.3E5), far in excess of what would be required for AFCs. This was therefore reduced in subsequent trials, although it should be noted that even in the third trial, the $\mathrm{Pu}$ stream still meets product specifications for current Thorp $\mathrm{Pu}$ products. The Pu DF on the U stream was fairly low in the first trial (1000). It has been noted earlier that the U product should meet criteria for either disposal as LLW, prolonged storage as $\mathrm{UO}_{3}$, or recycle, either in LWRs or as FR blanket fuel. The flowsheet therefore needs to be capable of producing high specification $U$ products, relatively free of TRU $\alpha$-activity. Modifications made in the later trials increased the Pu DF on the $\mathrm{U}$ stream to $1.45 \mathrm{E} 6$, despite increasing the $\mathrm{Pu}$ content in the HA feed to $100 \mathrm{~g} / \mathrm{l}$. Mass balances across the flowsheet were generally very good and percent recoveries excellent. These trials have given us great confidence that hydroxamic acids are very effective and robust reagents for $\mathrm{Np}+\mathrm{Pu}$ recovery across a broad range of AFC scenarios.

\section{Conclusions}

The Purex process has been the basis of nuclear fuel reprocessing schemes since the 1950s and there is now substantial successful operational experience at industrial scales coupled with a large historic knowledge base. However, further enhancements to the process are still of significant value, particularly in the context of developing technologies for TRU actinide recycle in AFCs and Generation IV reactors.

In particular, the separation of trivalent actinides from the lanthanides has been a major challenge to aqueous processing, involving the design of new extractants capable of exploiting the small differences in covalency between $4 \mathrm{f}$ and $5 \mathrm{f}$ elements. Much progress has been made internationally in demonstrating the technical feasibil- 


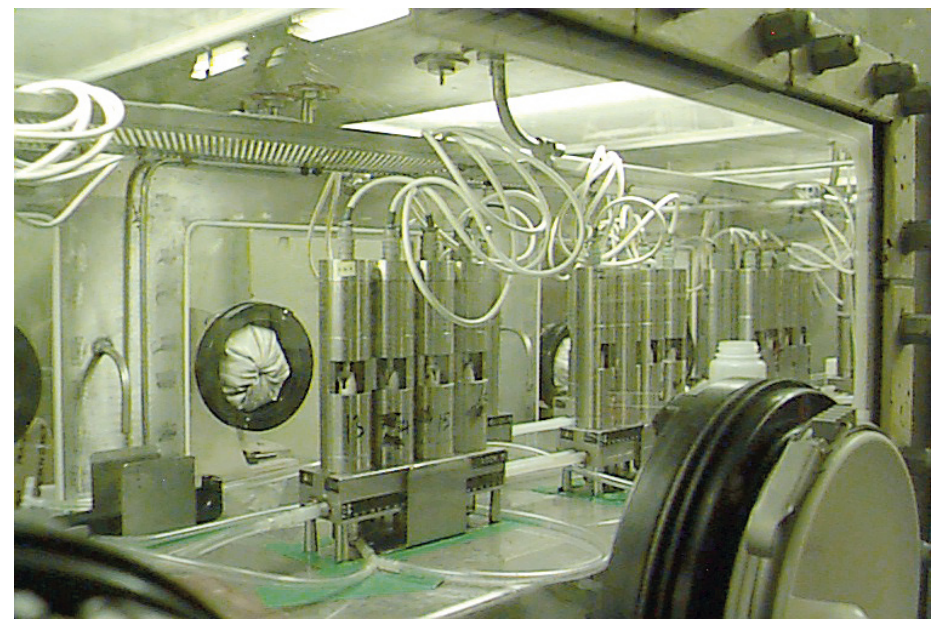

Fig. 4. Image of the 28-stage miniature centrifugal contactor rig, contained within a Pu glovebox at Nexia Solutions laboratories, BNFL, Sellafield

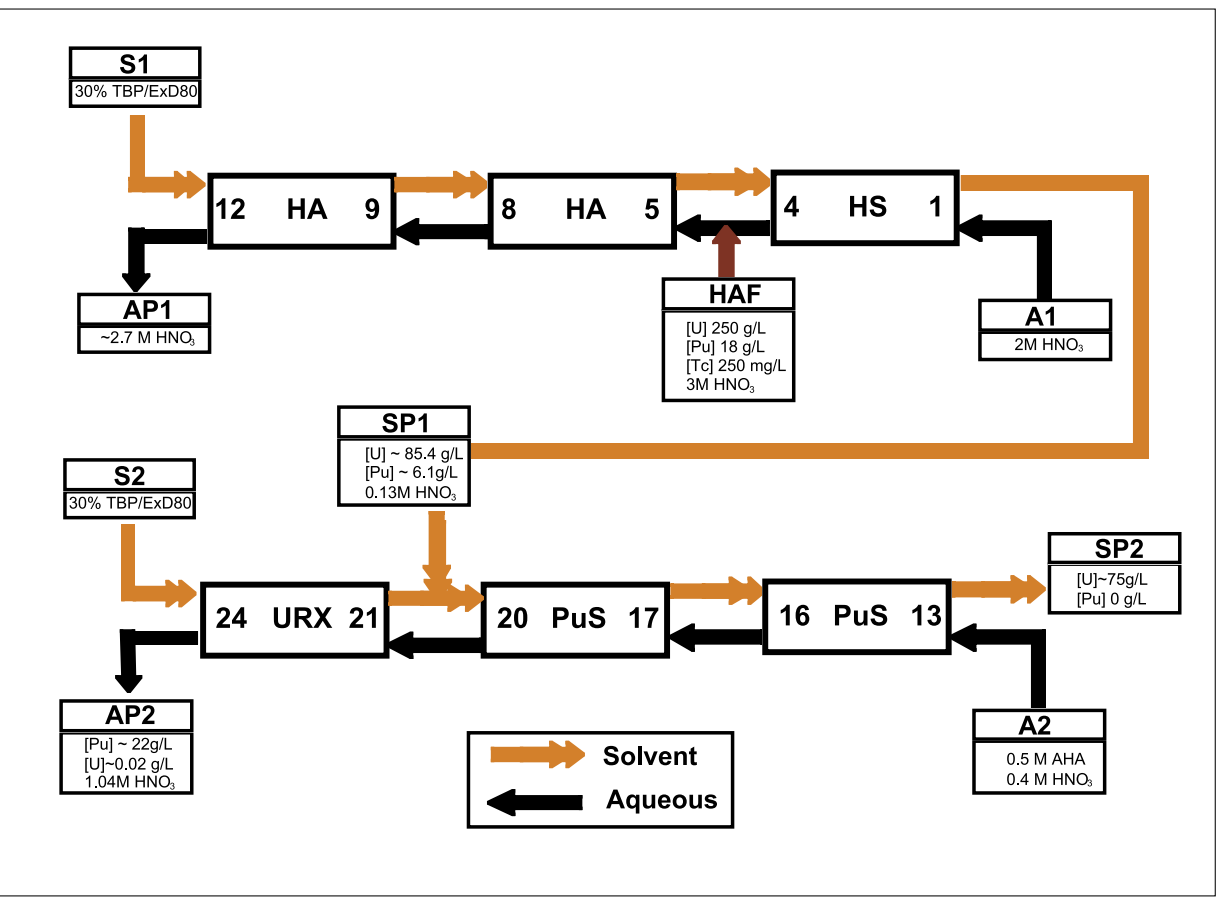

Fig. 5. Example chemical separation flowsheet designed to separate $U$ from Pu using acetohydroxamic acid (7 wt.\% Pu feed). [The nomenclature adopted is from conventional Purex solvent extraction cycles: HAF = Highly Active Feed; HA/HS = Highly Active extract and Scrub; AP/SP = Aqueous/ Solvent Product; A/S = Aqueous/ Solvent feed; URX = Uranium Re-eXtract; PuS = Plutonium Strip].

Table 2. U/Pu separation flowsheets: Key data from flowsheet trials $(7,20$, and 40 wt. \% Pu feeds, respectively).

$\begin{array}{lccc} & \text { Trial 1 } & \text { Trial 2 } & \text { Trial 3 } \\ {[\mathrm{Pu}] \text { in HAF }[\mathrm{g} / \mathrm{l}]} & 18 & 55.2 & 99.6 \\ \mathrm{Pu}] \text { in HAR }(\mathrm{g} / \mathrm{l}) & 0.0041 & 0.0018 & 0.0017 \\ \mathrm{Pu} \% \text { recovery } & >99.97 & >99.995 & >99.99 \\ \mathrm{U} \% \text { recovery } & >99.999 & >99.999 & >99.999 \\ \text { U stream Pu DF } & 1000 & 60000 & 1.45 \mathrm{E}+06 \\ \text { Pu stream U DF } & 1.30 \mathrm{E}+05 & 5500 & 360 \\ \text { Mass balance Pu [\%] } & 107.7 & 97.8 & 97.1 \\ \text { Mass balance U [\%] } & 98.4 & 101.4 & 99\end{array}$

ity of such new partitioning flowsheets.

The development of advanced Purex processes that achieve $\mathrm{U}, \mathrm{Np}$, and $\mathrm{Pu}$ recovery within a single solvent extraction cycle, using centrifugal contactors for phase mixing and separation and that meet the criteria for AFCs set out in Table 1 is also a significant challenge. Simple hydroxamic acids have been shown to be extremely useful reagents in this context.

Received: August 18, 2005

[1] P.D. Wilson, 'The Nuclear Fuel Cycle', Oxford University Press, Oxford, 1996.

[2] J.H. Miles, in 'Science and Technology of Tributyl Phosphate' Volume III, Part II, Ed. W.W. Schulz, J.D. Navratil, CRC Press, Florida, 1990, p. 11.

[3] G.R. Choppin, in 'Chemical Separations in Nuclear Waste Management', Ed. G.R. Choppin, M.K. Khankhasayev, H.S. Plendl, Battelle Press, Columbus, 2002, p. 3.

[4] H.A.C. McKay, J.H. Miles, J.L. Swanson, in 'Science and Technology of Tributyl Phosphate' Volume III, Part II, Ed. W.W. Schulz, J.D. Navratil, CRC Press, Florida, 1990, p. 1.

[5] Nuclear Energy Agency, 'Trends in the Nuclear Fuel Cycle', OECD, Paris, 2001.

[6] H. Takano, T. Ikegami, in 'Actinide and Fission Product Partitioning and Transmutation, 7th Information Exchange Meeting, Jeju, Republic of Korea, 14-16 October, 2002', Nuclear Energy Agency, OECD, Paris, 2003, p. 23.

[7] http://gen-iv.ne.doe.gov/.

[8] B. Savage, in 'Proc. Int. Conf. Atalante 2004, Advances for Future Nuclear Fuels Cycles', CEA, Nimes, 2004, Inv-06.

[9] J.W. Herczeg, in 'Actinide and Fission Product Partioning and Transmutation, 7th Information Exchange Meeting, Jeju, Republic of Korea, 14-16 October, 2002', Nuclear Energy Agency, OECD, Paris, 2003, p. 37.

[10] D. Warin, in 'Actinide and Fission Product Partioning and Transmutation, 7th Information Exchange Meeting, Jeju, Republic of Korea, 14-16 October, 2002', Nuclear Energy Agency, OECD, Paris, 2003, p. 53.

[11] G.R. Choppin, in 'Chemical Separations in Nuclear Waste Management', Ed. G.R. Choppin, M.K. Khankhasayev, H.S. Plendl, Battelle Press, Columbus, 2002, p. 49.

[12] J.J. Laidler, J.C. Bresee, in 'Proc. Int. Conf. Atalante 2004, Advances for Future Nuclear Fuels Cycles', CEA, Nimes, 2004, O11-01.

[13] K. Nomura, A. Shibata, A. Aoshima, in 'Proceedings of the International Symposium NUCEF 2001 - Scientific basis for criticality safety, separation process and waste disposal', Ed. T. Banba, Y. Tsubata, JAERI-Conf 2002-004, Tokai-Mura, 2002, p. 213. 
[14] B.C. Hanson, R.J. Taylor, P. Parkes, Nucl. Ener. 1999, 38, 37.

[15] A. Aoshima, Y. Koma, K. Nomura, M. Takanashi, Y. Sano, in 'Proc. Global 2001, International Conference on Back End of the Fuel Cycle from Research to Solutions', France, 2001, O46.

[16] J.J. Laidler, Prog. Nucl. Ener. 2001, 38, 65

[17] G. Uchiyama, H. Mineo, T. Asakura, S. Hotoku, M. Lizuka, S. Fujisaki, H. Isogai, Y. Itoh, M. Sato and N. Hosoya, in 'Proceedings of the International Symposium NUCEF 2001 - Scientific basis for criticality safety, separation process and waste disposal', Ed. T. Banba, Y. Tsubata, JAERI-Conf 2002-004, Tokai-Mura, 2002, p. 197.

[18] B.Ya. Zilberman, Yu.S. Federov, L.V. Sytnik, O.V. Shmidt, D.N. Kukharev, N.D. Goletsky, R.G. Glekov, Yu.V. Palenik, S.Yu. Sukhareva, in 'Proceedings of the International Symposium NUCEF 2001 - Scientific basis for criticality safety, separation process and waste disposal', Ed. T. Banba, Y. Tsubata, JAERI-Conf 2002004, Tokai-Mura, 2002, p. 189.

[19] R.J. Taylor, I. May, I.S. Denniss, A.L. Wallwork, G. Hunt, S. Hutchison, V. Richards, N.J. Hill, in 'Proc. of the 5th International Nuclear Conference on Recycling, Conditioning and Disposal, RECOD 98', French Nuclear Society (SFEN) and European Nuclear Society (ENS), Nice, 1998, p. 417.

[20] The structures of some of the leading extractants are illustrated in Fig. 2.

[21] L. Berthon, J.M. Morel, N. Zorz, C. Nicol, H. Virelizier, C. Madic, Sep. Sci. Technol. 2001, 36, 709.

[22] P. Baron, C. Rostaing-Nicol, C. Hill, X. Heres, B. Cames, L. Berthon, H. Roussel, P. Guilbaud, M. Lecomte, M. Masson, J-N Calor, G. Ferlay, C. Madic, CEA ATLANTE: Rapport Scientifique 2002, p. 76.

[23] D. Serrano-Purroy, B. Christiansen, R. Malmbeck, J.P. Glatz, P. Baron, C. Madic, in 'Proc. Int. Conf. Atalante 2004, Advances for Future Nuclear Fuels Cycles', CEA, Nimes, 2004, O12-03.

[24] C. Hill, D. Guillaneux, L. Berthon, C. Madic, in 'Proceedings of the International Symposium NUCEF 2001 - Scientific basis for criticality safety, separation process and waste disposal', Ed. T. Banba, Y. Tsubata, JAERI-Conf 2002-004, TokaiMura, 2002, p. 573.

[25] C. Hill, C. Roube, in 'Proceedings of the International Symposium NUCEF 2001 - Scientific basis for criticality safety, separation process and waste disposal', Ed. T. Banba, Y. Tsubata, JAERI-Conf 2002004, Tokai-Mura, 2002, p. 567.

[26] C. Hill, D. Guillaneux, L. Berthon, C. Madic, in 'Proceedings of the International Symposium NUCEF 2001 - Scientific basis for criticality safety, separation process and waste disposal', Ed. T. Banba, Y.
Tsubata, JAERI-Conf 2002-004, TokaiMura, 2002, p. 217.

[27] C. Madic, in 'Actinide and Fission Product Partioning and Transmutation, Sixth Information Exchange Meeting, Madrid, Spain, 11-13 December 2000', Nuclear Energy Agency, OECD, Paris, 2001, p. 53.

[28] C. Madic, M.J. Hudson, J.O. Liljenzin, J.P. Glatz, R. Nannicini, A. Facchini, Z. Kolarik, R. Odoj, 'New Partioning Techniques for Minor Actinides, Final Project Report', EUR 19149 EN, European Communities, Belgium, 2000.

[29] P. Chaix, C. Madic, J.-F. Aranyossy, in 'Proc. Global 2003, Atoms for Prosperity: Updating Eisenhower's Global Vision for Nuclear Energy', New Orleans, 2003.

[30] C. Madic, M. Lecomte, F. Testard, M.J. Hudson, J.-O. Liljenzin, B. Satmark, M. Ferrando. A. Facchini, A. Geist, G. Modolo, A. Gonzalez-Espartero, J. De Mendoza, in 'Proc. Global 2001, International Conference on Back End of the Fuel Cycle from Research to Solutions', France, 2001, 300 .

[31] V.P. Bhatnagar, S. Casalta, M. Hugon, in 'Actinide and Fission Product Partioning and Transmutation, Seventh Information Exchange Meeting, Jeju, Republic of Korea, 14-16 October 2002', Nuclear Energy Agency, OECD, Paris, 2003, p. 77.

[32] G.F. Vandegrift, M.C. Regalbuto, S. Aase, H. Arafat, A. Bakel, D. Bowers, J.M.A. Clark, J.W. Emery, J.R. Falkenberg, A.V. Gelis, C. Pereira, L. Hafenrichter, Y. Tsai, K.J. Quigley, M.H. Vander Pol, in 'Proc. Int. Conf. Atalante 2004, Advances for Future Nuclear Fuels Cycles', CEA, Nimes, 2004, O12-01.

[33] J.D. Law, T.A. Todd, D.R. Peterman, R.S Herbst, R.D. Tillotson, in 'Proc. Int. Conf. Atalante 2004, Advances for Future Nuclear Fuels Cycles', CEA, Nimes, 2004, O12-06.

[34] Y. Koma, T. Koyama, Y. Tanaka, in 'Proc. of the 5th International Nuclear Conference on Recycling, Conditioning and Disposal, RECOD 98', French Nuclear Society (SFEN) and European Nuclear Society (ENS), Nice, 1998, p. 409.

[35] O. Amano, F. Kawamura, T. Fukasawa, A Sasahira, in 'Proceedings of the International Symposium NUCEF 2001 - Scientific basis for criticality safety, separation process and waste disposal', Ed. T. Banba, Y. Tsubata, JAERI-Conf 2002-004, TokaiMura, 2002, p. 217.

[36] Nuclear Energy Agency, 'Actinide and Fission Product Partioning and Transmutation, Seventh Information Exchange Meeting, Jeju, Republic of Korea, 14-16 October 2002', Paris, Nuclear Energy Agency, OECD, 2003.

[37] Nuclear Energy Agency, 'Actinide and fission product partitioning and transmutation, Sixth Information Exchange Meeting Madrid, Spain, 11-13 December 2000',
Nuclear Energy Agency, OECD, Paris, 2001.

[38] Nuclear Energy Agency, 'Actinide and fission product partitioning and transmutation, Status and assessment report', OECD, Paris, 1999.

[39] R.J. Taylor, in 'Advances in Actinide Science', Royal Society of Chemistry, forthcoming.

[40] M.P. Brossard, J.M. Belmont, P. Baron, P. Blanc, J.C. Broudic, J.Y. Chapelet, G. Bourges, C. Leloup, in 'Proc. Atalante 2004, International Conference on Advances for Future Nuclear Fuels Cycles', CEA, France, 2004.

[41] E.M. Glagovsky, A.V. Kouprin, L.P. Pelevin, S.V. Yudintsev, E.E. Konovalov, in 'Proc. Global 2001, International Conference on Back End of the Fuel Cycle from Research to Solutions', France, 2001, O39.

[42] i.e. reagents containing carbon, hydrogen, oxygen and nitrogen only.

[43] G. Petrich, in 'Proc. Int. Solv. Extr. Conf. ISEC 90', Ed, T. Sekine, 1992, p. 355.

[44] H. Schmieder, Radiochim Acta 1989, 48 , 181.

[45] R.J. Taylor, I. May, A.L. Wallwork, I.S. Denniss, N.J. Hill, B.Ya. Galkin, B.Ya. Zilberman, Yu. S. Fedorov, J. Alloys \& Compounds 1998, 271-273, 534.

[46] R.J. Taylor, J. Nucl. Sci. Tech. 2002, Supp. 3,886 .

[47] J.E. Birkett, M.J. Carrott, G. Crooks, C.J. Maher, O.D. Fox, C.J. Jones, C.V. Roube, R.J. Taylor, D. Woodhead, in 'Advances in Actinide Science', Royal Society of Chemistry, forthcoming.

[48] O.D. Fox, C.J. Jones, J.E. Birkett, M.J. Carrott, C.J. Maher, C.V. Roube, R.J. Taylor, in 'Actinide Separations for the 21st Century', ACS, forthcoming.

[49] I. May, R.J. Taylor, G. Brown, J. Alloys \& Compounds 1998, 271-273, 650.

[50] A. Barocas, F. Baroncelli, G.B. Biondi, G. Grossi, J. Inorg. Nucl. Chem. 1966, 28, 2961.

[51] F. Baroncelli, G. Grossi, J. Inorg. Nucl. Chem. 1965, 27, 1085.

[52] K.N. Raymond, G.E. Freeman, M.J. Kappel, Inorg. Chim. Acta 1984, 94, 193.

[53] P.W. Durbin, N. Jeung, S.J. Rodgers, P.N Turowski, F.L. Weitl, D.L. White, K.N Raymond, Rad. Prot. Dos. 1989, 26, 351.

[54] I. May, R.J. Taylor, I.S. Denniss, G. Brown, A.L. Wallwork, N.J. Hill, J.M. Rawson, R. Less, J. Alloys \& Compounds 1998, 275 277, 769.

[55] O.D. Fox, R.J. Taylor, in 'Pu Futures - the science conference', Ed. G. Jarvinen, American Institute of Physics Conference Proceedings, 273, New York, 2003, p. 282. 